\title{
Território e Desigualdades de Renda em Regiões Metropolitanas do Brasil*
}

\section{Marcelo Gomes Ribeiro}

Universidade Federal do Rio de Janeiro (UFRJ), Rio de Janeiro, RJ, Brasil. E-mail: marceloesmeraldino@gmail.com

\section{INTRODUÇÃO}

$\mathrm{E}$ ste artigo tem como objetivo contribuir analiticamente com o debate acerca das desigualdades de renda nas regiões metropolitanas brasileiras, incorporando nos seus determinantes explicativos a importância da localização residencial na metrópole para uma compreensão mais ampla dessas desigualdades que, normalmente, tendem a considerar somente as características próprias dos indivíduos, sejam aquelas adscritas, como cor / raça e sexo, sejam as adquiridas, como a escolaridade.

No momento em que o Brasil passou por transformações significativas na sua estrutura econômica, como ocorreu nos anos 1990, o que colaborou para o aumento das desigualdades no país, a educação passou a ser reivindicada como o mecanismo por excelência para reverter esse quadro. Nesse contexto, o desemprego tornou-se o principal fenômeno social a ocupar as preocupações tanto dos formuladores das políticas públicas, quanto dos pesquisadores sociais que tratam de temas relativos ao mundo do trabalho. A focalização no fenômeno do desemprego de-

\footnotetext{
* Este artigo é uma versão modificada de parte da minha tese de doutorado, Educação, estrutura social e segmentação residencial do território metropolitano: análise das desigualdades de renda do trabalho em regiões metropolitanas do Brasil, e foi apresentado no 37ํㅡㄹ Encontro Anual da Associação Nacional de Pós-Graduação e Pesquisa em Ciências Sociais (Anpocs), Águas de Lindóia, SP, 23-27 de outubro de 2013.
}

DADOS - Revista de Ciências Sociais, Rio de Janeiro, vol. 58, no-4, 2015, pp. 913 a 949. 
correu do seu aumento generalizado, principalmente nas metrópoles brasileiras, onde se concentrava o setor industrial.

Nos últimos anos, porém, em decorrência da redução da taxa de desemprego e do aumento do emprego formal, o foco de discussão foi redirecionado para as desigualdades de renda do país. As análises, de modo geral, têm enfatizado a redução das desigualdades de renda entre os grupos sociais, medida tanto através de indicadores sintéticos como o índice de Gini e de Theil-, quanto de outras formas, como as diferenças entre os estratos de renda. De qualquer modo, o que se consegue apreender das análises efetuadas é que o país precisa reduzir ainda mais as desigualdades que o caracterizam historicamente, para alcançar patamares dos países mais desenvolvidos.

Tanto no momento em que o desemprego tornou-se a tônica das discussões políticas e acadêmicas (Guimarães e Cardoso, 2008), quanto noutro, mais recente, em que as desigualdades de renda tornaram-se o principal tema de debate público, ocorreu a utilização mais explícita da teoria do capital humano (Barros, Franco e Mendonça, 2007; Barbosa Filho e Pessôa, 2009), seja para justificar o insucesso de boa parcela de indivíduos que procuravam uma inserção no mercado de trabalho e não conseguiam, seja para demonstrar o motivo das diferenças de renda entre os indivíduos.

A teoria do capital humano obtém muita relevância, sobretudo nas conjunturas que estamos mencionando, porque possui um pressuposto que é muito fácil de ser compreendido intuitivamente: indivíduos com maior nível de escolaridade apresentam maior nível de remuneração (Schultz, 1961; Mincer, 1974). De fato, quando se utiliza qualquer base de dados que possua informações relativas à renda e escolaridade, as análises vão sempre indicar que há uma correlação positiva entre essas duas variáveis, o que possibilita concluir que o nível de renda é, em grande medida, decorrente da escolaridade. É claro que grau de correlação não implica, necessariamente, relação de causalidade. Porém, independente disso, é importante ressaltar que, se há alguma causalidade entre os dois fenômenos mencionados, torna-se importante compreender os mecanismos que operam no sentido de tornar os mais escolarizados os que também possuem, em média, as maiores rendas, já que se trata da relação entre dois fenômenos sociais.

Avanços nesse sentido já foram realizados ao procurar demonstrar que a seleção de mão de obra demandada pelo mercado de trabalho, basea- 
da no critério de escolaridade, tem implícita a escolha referente à posição social dos indivíduos (Collins, 1971; Bourdieu, 2007), que, em situações de inflação de credenciais educacionais, o mercado de trabalho, ao demandar mão de obra, seleciona os indivíduos que apresentam os melhores atributos adquiridos, mesmo em circunstâncias em que a escolaridade apresentada é maior que a exigência da ocupação. Nesse caso, ocorre a existência de filas ordenadas segundo os atributos dos indivíduos (Thurow, 1972).

Também foi desenvolvida, desde o começo dos anos 1980, uma importante contribuição analítica que procurou focalizar as exigências de escolaridade das ocupações em vez de tratar a escolaridade dos indivíduos (Duncan e Hoffman, 1981). O pressuposto desse modelo analítico é de que a escolaridade requerida pela ocupação é mais importante que a escolaridade do indivíduo. E, ao haver inflação de credenciais educacionais, dado o aumento generalizado do nível educacional da população, passa a ocorrer o aumento de situações de overeducation (sobre-educação), situação na qual as pessoas apresentam maior nível de escolaridade que o exigido pela ocupação.

Observamos que houve importantes avanços nesse campo analítico, em que se procurou analisar a relação da escolaridade e o nível de renda, tanto referente à oferta de trabalho, quanto à demanda por trabalho. Tanto numa dimensão quanto em outra foram feitas análises buscando também compreender os mecanismos que tornam os mais escolarizados os que, em média, recebem as maiores remunerações do trabalho. Assim, passou-se a destacar as condições sociais dos indivíduos como justificativas para sua inserção no mercado de trabalho e, por conseguinte, determinantes para explicação do nível de renda que obtêm. Essas condições sociais foram compreendidas, sobretudo, pela posição ocupada pelos indivíduos na estrutura social. Mas poucos avanços foram feitos no sentido de considerar a inscrição dessa estrutura no espaço físico, para entender a relação entre escolaridade e nível de renda, principalmente quando consideramos os contextos urbano-metropolitanos. Assim, se a estrutura social se retraduz no espaço físico (Bourdieu, 1997), sobretudo em contextos metropolitanos, torna-se importante inserir na análise a localização residencial dos indivíduos na metrópole para ampliar a compreensão da relação entre escolaridade e nível de renda.

Por isso, na perspectiva de avançar nesse debate, pretendemos responder, aqui, as seguintes perguntas: 
1. A segmentação residencial do território metropolitano, referida pelo local de moradia dos indivíduos, é relevante na explicação das diferenças de renda obtida no mercado trabalho? Se sim, quais são os mecanismos territoriais que explicam essas desigualdades?

2. O efeito território se dá do mesmo modo entre todas as regiões metropolitanas brasileiras? Ou há diferenças entre elas? Neste caso, o que explicaria essas diferenças?

Como hipóteses a essas questões, consideramos que a segmentação residencial tem efeito na explicação das desigualdades de renda. A explicação do território para obtenção de renda pessoal pode ser mediada pela estrutura educacional (segundo a escolaridade) existente em cada contexto territorial, ou pelo modo como a estrutura social se inscreve no espaço físico das metrópoles brasileiras. Os mecanismos explicativos da relação entre território e obtenção de renda podem estar associados aos modelos do efeito vizinhança (Wilson, 1987; Ellen e Turner, 1997; Small e Newman, 2001), que colabora para reforçar o padrão de segmentação residencial das metrópoles brasileiras compreendido na dupla escala da divisão social do território: por um lado, modelo centro-periferia, em que há correspondência entre distância física e distância social, e, por outro, modelo favela-não favela, onde há proximidade física e distância social (Ribeiro, 2008; Ribeiro e Koslinski, 2009).

Mas é preciso também considerar que os condicionamentos socioterritoriais podem se caracterizar de modo diferente dependendo do contexto regional em que cada metrópole está inserida. Isso é relevante porque a formação social de cada metrópole no Brasil, apesar de seguir o padrão característico das metrópoles latino-americanas, conforma estruturas sociais e econômicas diferentes entre si, o que pode contribuir para diversas formas de interpretação dos mecanismos do território metropolitano como fenômeno que ajuda a explicar as desigualdades de renda.

Este artigo está organizado em seis seções, incluída esta Introdução. Na segunda seção, discutimos as duas categorias representativas da segmentação residencial do território das metrópoles brasileiras: favela e periferia. Na terceira, apresentamos os pressupostos teóricos referentes ao efeito território em contextos metropolitanos para análise das desigualdades observadas entre os diversos grupos sociais existentes. Na quarta seção, apresentamos os modelos analíticos aqui utilizados com a finalidade de testar as hipóteses levantadas e os proce- 
dimentos metodológicos realizados. Na quinta, apresentamos a aplicação dos modelos analíticos utilizados e realizamos análise dos resultados encontrados à luz dos pressupostos teóricos utilizados. Por fim, nos comentários finais, discutimos a dimensão escalar da segmentação residencial para estudos sobre desigualdades sociais e territoriais, na perspectiva de apontar desdobramentos possíveis nesse campo de estudo.

\section{SEGMENTAÇÃO RESIDENCIAL METROPOLITANA: DUPLA ESCALA DA DIVISÃO SOCIAL DO TERRITÓRIO}

Duas categorias frequentemente utilizadas no Brasil foram socialmente construídas para identificar o caráter particular do modo como se manifestou a segregação socioespacial nas metrópoles brasileiras: periferia e favela. Embora essas categorias expressassem noções distintas a respeito das desigualdades territoriais metropolitanas e tenham surgido em momentos diferentes na sociedade brasileira, ambas foram capazes de representar posições sociais relacionais com outros lugares materializadas no espaço físico, tendo o poder de denunciar as desigualdades territoriais metropolitanas ao contribuir para a constituição do que se convencionou chamar de questão urbana. Essas noções conferem ao tratamento da organização social do território metropolitano brasileiro de um modo particular que pode ser compreendido, de um lado, pela relação centro e periferia e, de outro, pela proximidade física e distância social (Ribeiro, 2008).

A noção de periferia passou a ganhar conotação relevante na sociedade brasileira e se construiu socialmente, sobretudo, em decorrência do processo de urbanização ocorrida no país, que manifestava a diferença das condições sociais das pessoas que não conseguiam moradia nas proximidades do local de trabalho, tendo que buscar alternativas em bairros mais distantes do centro da cidade ou mesmo em outros municípios das regiões metropolitanas. Essas condições sociais eram manifestadas pela carência de infraestrutura urbana que se realizavam, em grande medida, em loteamentos clandestinos, distantes do local de trabalho.

A questão urbana que emergiu, decorrente da identificação da periferia como categoria social capaz de denunciar o modo como se realizava a urbanização na sociedade brasileira, deu centralidade à inexistência ou precariedade de moradia para parcela expressiva dos migrantes 
que se dirigiam aos principais centros urbanos do país em busca de trabalho. Ou seja, a compreensão dessa questão urbana se deu pela relação entre moradia e trabalho. Era em torno da problemática do trabalho que a ausência ou precariedade da moradia passou a ser compreendida, dando primazia à periferia como lugar em que se constituiu como alternativa para reprodução da mão de obra e, por isso mesmo, servisse de barateamento da força de trabalho.

Mas essa identificação das condições precárias em que se assentava a população que vivia nas periferias das grandes cidades, sobretudo São Paulo e Rio de Janeiro, ganhou expressão relevante como categoria que dimensionava a problemática urbana ou o tipo de urbanização que se realizava no Brasil - e por que não dizer na América Latina? - quando passou a ser associada à concepção de espoliação urbana (Arantes, 2009).

A espoliação urbana foi originalmente formulada como:

Somatório de extorsões que se opera através da inexistência ou precariedade de serviços de consumo coletivo que se apresentam como socialmente necessários em relação aos níveis de subsistência e que agudizam ainda mais a dilapidação que se realiza no âmbito das relações de trabalho. (Kowarick, 1979:59)

A espoliação urbana revelou, assim, as condições de exploração social do urbano que se realizavam naquele período pelo processo de periferização em curso nas metrópoles brasileiras, sobretudo nos principais centros urbanos. Ela deu à categoria periferia a carga política que denunciava as contradições do modo como se realizava a urbanização e, por conseguinte, a metropolização brasileira.

É evidente que esse processo de urbanização e metropolização já estava em curso no país desde os anos 1930, intensificando-se a partir das décadas de 1950/1960, apesar de diferenças temporais entre os principais centros urbanos que mais tarde se constituíram como metrópoles. Mas, de modo geral, a sua explicação como um fenômeno urbano particular da nossa sociedade, que retratava o caráter das desigualdades no território metropolitano, só veio a ganhar esses contornos a partir do final dos anos 1970 e começo dos anos 1980.

A noção de favela, por outro lado, teve uma história muito mais antiga que a de periferia. Foi um fenômeno que apareceu na virada do século XIX para o XX, mas sua construção social como um problema urbano 
ocorreu, sobretudo, a partir da segunda década do século XX, vinculada à concepção higienista predominante naquele momento na cidade do Rio de Janeiro. Mais tarde somou-se à concepção sanitarista também a preocupação estética com a cidade, em que recaiu sobre a favela um dos males a serem combatidos (Valladares, 2000).

Nos anos 1930, sobretudo a partir do surgimento do Estado Novo, a favela passou a ser preocupação também da política de assistência social daquele momento, na medida em que o governo getulista, ao compreender a necessidade de controle dos trabalhadores, entendia como necessário conhecer a favela para poder também controlá-la. E, nesse sentido, a assistência social foi o mecanismo por excelência para cumprir essa tarefa. Foi também nesse período que ocorreu pela primeira vez o reconhecimento institucional da favela, quando esta passou a ser mencionada no código de obras da cidade do Rio de Janeiro (idem). A investigação e o aprofundamento sobre as favelas passaram a ganhar maior sistematicidade somente a partir dos anos 1950, decorrente, inclusive, da divulgação naquele momento do censo demográfi$\mathrm{co}$, que pela primeira vez apresentou dados referentes à favela (denotado como aglomerados subnormais).

Durante todo esse período, a favela foi compreendida como um problema a ser solucionado na cidade do Rio de Janeiro, ao mesmo tempo que se tinha sobre ela uma compreensão homogeneizante, no sentido de considerar que no seu interior as pessoas possuíam as mesmas condições sociais e que todas as favelas apresentavam semelhanças. Mas também por decorrência de investigações que se desenvolveram a partir dos anos 1950/1960, a explicação para o fenômeno da favela passou a ser associada às condições sociais das pessoas, às dificuldades de obtenção de moradia e, ao mesmo tempo, à proximidade com o mercado de trabalho. Foi somente a partir do final dos anos 1960 e começo dos anos 1970, que a heterogeneidade social (e política) da favela passou a ser reconhecida (Silva, 2011; Perlman, 1977).

Como um fenômeno particular que se originou no Rio de Janeiro, expressão da segregação social e, ao mesmo tempo, da proximidade territorial, a categoria favela passou a ser associada ao modo como se deu o processo de urbanização e metropolização no país e foi disseminada como representação para as situações de pobreza manifestada pelas condições sociais e de infraestrutura precárias em enclaves do território metropolitano. Ou seja, mesmo que em regiões metropolitanas 
específicas do Brasil se fizesse uso de terminologias próprias para designar certos tipos de aglomerados existentes nas cidades, a representação social de favela acabou servindo como referencial para sua compreensão.

Tanto a categoria periferia quanto a categoria favela constituíram-se como representações do modo particular da segregação socioespacial nas metrópoles brasileiras, sendo sempre acionadas para explicação das desigualdades territoriais urbanas. Ainda que não apresentem o mesmo conteúdo que lhes foram incorporadas entre os anos 1960 e 1980, sobretudo depois das mudanças estruturais ocorridas no país, essas categorias continuam servindo como referência nos estudos urbanos, mesmo que seja para interrogar o padrão de segregação socioespacial da atualidade em contraposição ao que se constituiu no bojo da política de substituição de importações.

Além disso, essas categorias expressam escalas diferentes de manifestação da segmentação socioespacial nas metrópoles brasileiras. Isso é importante porque os mecanismos geradores de desigualdades sociais, por decorrência da natureza específica de cada um dos fenômenos sociais, podem ser apreendidos ou na macroescala, retratados pelo conceito de periferia, ou na microescala, retratados pelo conceito de favela.

As categorias periferia e favela, que serviram como caracterização da segmentação residencial do território metropolitano no Brasil, mesmo tendo sofrido questionamento quanto ao seu conteúdo, continuam sendo referência para designação do modo particular como se caracteriza a segregação socioespacial nas metrópoles brasileiras. É nesse sentido que procuramos utilizar essas categorias na análise deste artigo, ao compreender que seu significado pode ter sofrido mudança decorrente dos processos históricos em que essas categorias sociais se inscreveram, mas que, ao mesmo tempo, continuam tendo validade para interpretação dos fenômenos socioespaciais nas metrópoles brasileiras.

\section{TEORIAS EXPLICATIVAS DO EFEITO TERRITÓRIO}

Como as metrópoles brasileiras se constituíram espacialmente configurando posições territoriais e escalares distintas, no que ficou conhecido como modelo centro-periferia, por um lado, e "favela-não favela", por outro, interessa observar as contribuições teóricas que possibilitam analisar a validade desses modelos socioespaciais para explicação das desigualdades de rendimento observadas no mercado de trabalho. 
Desde a década de 1970 já havia se configurado avanços nos estudos urbanos que procuravam compreender a distribuição de renda entre os indivíduos por decorrência, de um lado, da distribuição das atividades dispostas numa determinada forma urbana e, de outro, das mudanças ocorridas nessa forma urbana, podendo beneficiar determinados grupos sociais em detrimento do constrangimento de outros. Essa distribuição de renda pode ser concebida pelas trocas monetárias propriamente ditas, tendo em vista o preço que se paga, por exemplo, pela distância entre o local de moradia e o local de trabalho; mas também pode ser compreendida pelo aumento (ou diminuição) de renda por decorrência de efeitos externos, configurando o que foi designado por David Harvey (1980) como renda real.

As perspectivas teóricas elaboradas para compreensão dos mecanismos que tornam o território metropolitano importante para a explicação de outros fenômenos sociais foram desenvolvidas principalmente nos Estados Unidos, em decorrência do surgimento dos guetos norteamericanos que ganharam destaque, sobretudo, a partir dos anos 1980, sob a denominação de efeito vizinhança (neighborhood effect); mas também podemos observar contribuições nesse sentido de países europeus, em especial da França, onde houve a presença de pesquisadores que trataram do efeito bairro.

Tanto de um lado quanto de outro do Atlântico os pesquisadores que consideraram o efeito território (efeito bairro ou neighborhood effect) estavam preocupados em compreender o efeito que determinado contexto social de moradia (vizinhança ou bairro) possuía sobre diversos aspectos da vida social dos indivíduos, como as chances de sucesso escolar, as oportunidades de emprego, dentre outros aspectos, que normalmente colocavam em desvantagem determinados coletivos humanos.

Essa perspectiva analítica, apesar de ter se configurado na primeira metade do século $\mathrm{XX}$, quando foram desenvolvidos os primeiros estudos da chamada Escola de Chicago, ganhou ênfase a partir dos anos 1980, decorrente do trabalho apresentado por W. J. Wilson - The Truly Disadvantaged: The Inner City, the Underclass, and the Public Policy (1987) -, em que procurou pôr em questão as explicações da pobreza na inner city de Chicago, colaborando para uma perspectiva de análise de teor mais estruturalista. 
$\mathrm{Na}$ época em que Wilson escreveu essa obra, estava se disseminando na sociedade norte-americana a explicação para a pobreza urbana como decorrente da cultura da pobreza, associada a uma concepção racial, no sentido de que a explicação para a condição social dos indivíduos decorria das normas e valores incorporados que não os predispunham para sair daquela situação. É o que justificava o fato de essa pobreza se reproduzir ao longo do tempo, segundo essa perspectiva, colaborando para o aumento da criminalidade, a elevação da taxa de gravidez na adolescência e fora do casamento e o incremento da taxa de desemprego, que se caracterizavam como comportamento desviante em relação às normas vigentes. A pobreza não apenas se fazia presente na inner city, que passou a se configurar como gueto, mas também tendia a se reproduzir. Esses coletivos populacionais em situação de pobreza eram caracterizados, sobretudo, por pessoas negras, que passaram a ser identificadas como underclass.

Contra essa perspectiva culturalista de explicação da pobreza urbana, Wilson procurou demonstrar que, em decorrência de mudanças significativas ocorridas na estrutura econômica das metrópoles norteamericanas, reconfigurando regionalmente a localização dos ramos industriais, muitas indústrias saíram para outras partes do país e do mundo, alterando, com isso, a composição da estrutura de emprego. A inner city que no passado era caracterizada pela existência de grupos sociais em condições econômicas diversas, em que prevalecia a mistura social, tendeu ao processo de homogeneização social com fluxo da classe média e dos trabalhadores que migraram seja para o subúrbio da metrópole seja para outras regiões do país, em busca da manutenção do emprego ou do mesmo padrão de vida, levando assim à concentração dos menos privilegiados.

Em contexto de condições sociais homogêneas, sob o mecanismo do isolamento social, observou-se, por um lado, a dificuldade dos adultos de conseguirem emprego tendo em vista a falta de qualificação necessária para as vagas existentes decorrentes das mudanças ocorridas no processo produtivo ou falta de informação de sua existência devido aos tipos de relacionamentos a que estavam submetidos, em que as pessoas de modo geral se encontravam nas mesmas condições sociais; e, por outro lado, o comportamento adquirido pelas crianças e adolescentes tendeu a se configurar tendo por parâmetro o modo de vida construído no gueto e, por elas, assimilado (modelo de papel). Em condições de mistura social, as crianças e adolescentes pobres poderiam 
desenvolver suas aspirações de vida por ter contato com pessoas que estivessem em padrão social mais elevado que o seu, mas, em condições homogêneas de pobreza, suas aspirações ficavam comprometidas porque percebiam os adultos na mesma situação em que viviam.

Ao se utilizar da concepção do mecanismo de isolamento social, Wilson procurou analisar como as condições sociais existentes na inner city, que perdurariam por vários anos, colaboraram para a reprodução da pobreza, ao discutir vários aspectos da vida dos indivíduos, tais como gravidez fora do casamento, gravidez na adolescência, desemprego, evasão escolar etc. Esse tipo de abordagem da pobreza colaborou para reconfigurar o debate na sociedade norte-americana, dando importância, desde então, para as análises territoriais na explicação das desvantagens sociais. A partir desse momento, emergiram vários estudos favoráveis e contrários à análise de Wilson, que passaram a considerar o efeito vizinhança (neighborhood effect).

Grande parte desses estudos atribuiu importância ao efeito da divisão social do território sob determinadas condições históricas para explicação das vantagens e desvantagens sociais observadas em moradores de um mesmo bairro, tanto em situações de pobreza quanto em situações de padrão mais elevado socialmente. Porém, mais do que perceber se o território importava na análise de determinados fenômenos sociais, tornou-se fundamental saber quais eram os mecanismos que contribuíam para compreender como o território provocava efeito sobre esses fenômenos. Essas questões, que de modo geral ainda estão abertas para determinados fenômenos que merecem ser melhor investigados, tomaram a agenda de boa parte dos pesquisadores que tratam da pobreza urbana.

De acordo com Ellen e Turner (1997), mediante um levantamento de várias pesquisas que até então foram realizadas e que procuraram incorporar em suas análises o efeito do território, há seis diferentes tipos de mecanismos que devem ser considerados para interpretação do modo como o território interfere nos resultados de alguns fenômenos sociais para indivíduos e famílias: qualidade dos serviços locais; socialização dos adultos; influência de pares; redes sociais; exposição ao crime e violência; distância e isolamento.

Os autores procuraram deixar claro, porém, que esses mecanismos podem interferir em estágios diferentes da vida dos indivíduos e, além disso, em qualquer estágio da vida nem todos os indivíduos serão afe- 
tados no mesmo grau pelo efeito do território. Isso porque esses mecanismos irão operar de acordo com as outras dimensões que afetam os resultados dos indivíduos, tanto familiar como individual.

Em relação aos mecanismos apontados, aqueles que mais contribuem para explicação de efeitos da vizinhança sobre a vida dos adultos referem-se às redes sociais e a distância e isolamento. O primeiro decorre da qualidade e extensão de relacionamentos que os indivíduos possuem, o que pode contribuir para obtenção de informação sobre oportunidades de emprego, mas também para participação cívica e política na sociedade. A análise das redes sociais deve considerar a característica do território onde se localizam as moradias dos indivíduos, se são homogêneos ou heterogêneos, e se a extensão dessas redes está além das relações de vizinhança. O segundo mecanismo - distância e isolamento - refere-se basicamente à distância física e acessibilidade para oportunidades econômicas, sobretudo oportunidades de emprego. Estar longe das oportunidades de emprego e não ter acesso a elas por falta de transporte público, por exemplo, afeta negativamente as chances dos indivíduos de obter um bom trabalho.

Small e Newman (2001) também realizaram um levantamento de trabalhos que utilizaram o efeito vizinhança para análise de vários fenômenos sociais. Dentre os estudos que identificaram, puderam constatar que, de modo geral, esses poderiam ser classificados segundo dois modelos gerais de mecanismos propostos para interpretação do efeito vizinhança. O primeiro compreende os mecanismos de socialização. Nesse sentido, procura examinar como a vizinhança socializa as pessoas que nela crescem, sugerindo que a vizinhança (ou o bairro) molda os indivíduos sob determinados modelos de comportamento. Por este motivo, esses mecanismos são utilizados em estudos realizados sobre crianças e adolescentes, tais como as chances de abandono escolar, gravidez na adolescência, entre outros.

O segundo modelo compreende os mecanismos instrumentais, cuja preocupação é analisar como a agência dos indivíduos é limitada pelas condições da vizinhança (ou do bairro). Por este motivo, esses mecanismos são utilizados para explicar o efeito vizinhança sobre fenômenos relacionados com adultos, ao invés de crianças e adolescentes. $\mathrm{O}$ mais proeminente desses mecanismos corresponde ao modelo de isolamento de redes sociais, que considera que os indivíduos em condições de pobreza e desemprego, em um bairro cuja população encon- 
tra-se na mesma situação, têm maiores dificuldades de encontrar informações referentes à vaga de emprego no mercado de trabalho. Outro importante mecanismo instrumental refere-se ao modelo de recursos, que sugere que, em bairros pobres, privados de recursos institucionais como escolas, igrejas, áreas de recreação, por exemplo, os pais têm maiores dificuldades de educar seus filhos.

Também na América Latina alguns estudos foram realizados, considerando o efeito do território (bairro ou vizinhança) para interpretação dos fenômenos sociais decorrentes das condições de pobreza urbana na região (Kaztman, 1999 e 2001). Esses estudos tomam como referência as contribuições realizadas nos Estados Unidos, principalmente o trabalho já mencionado de Wilson.

Os estudos realizados na América Latina sobre o efeito território ${ }^{1}$ utilizaram diferentes bases de dados, aplicaram métodos diversos para definição das condições sociais do bairro ou da vizinhança e também operaram de formas distintas, alguns com análises multinomiais, outros com análise linear, outros ainda com análise multiníveis (análise hierárquica). Isso demonstra que a operacionalização do instrumental teórico que permite analisar o efeito territorial se dá numa arena muito difusa e que ainda apresenta muitos desafios metodológicos. Mas, como podemos observar, essa não é uma preocupação apenas para os trabalhos realizados no contexto da América Latina. Segundo Small e Newman (2001), algumas dificuldades são encontradas nesse tipo de estudo que estão relacionadas com a distribuição populacional dos indivíduos, a definição da vizinhança ou do bairro e as características da vizinhança que serão consideradas para medir as desvantagens.

Ellen e Turner (1997) também fizeram um levantamento de pesquisas que consideram o efeito da vizinhança e constataram que, referente ao procedimento metodológico utilizado, há alguns desafios que precisam ser superados nos estudos que adotam essa perspectiva analítica: é difícil identificar e medir as condições do ambiente da vizinhança que desempenha um papel mais importante na formação dos resultados para as famílias e indivíduos; o efeito da vizinhança pode ser não linear e, por isso, não ser claramente discernível; é difícil separar o efeito da vizinhança do efeito da família, principalmente características que são difíceis de medir e observar.

Apesar de discutirem o motivo pelo qual esses aspectos referentes à metodologia desafiam as pesquisas que utilizam o efeito vizinhança e 
de apreenderem que essa dimensão importa para análise de determinados fenômenos sociais, os autores reconhecem a dificuldade de superá-los e apontam diferentes usos feitos nas pesquisas para tentar contornar esses desafios. Porém, tanto na análise feita por Ellen e Turner (1997) quanto na avaliação de Small e Newman (2001), a preocupação na discussão desses aspectos metodológicos está relacionada ao fato de a vizinhança ou o bairro serem territórios construídos socialmente, embora se estabeleçam barreiras geográficas em suas definições. Pela imposição dos dados que serão utilizados, tendo em vista o modo como estão disponibilizados, a análise do território metropolitano que considera o aporte conceitual e teórico do efeito vizinhança e seus mecanismos deve ser feita considerando as distâncias existentes entre o conteúdo teórico dos conceitos e o modo como o território é empiricamente apreendido.

Isso é inteiramente significativo para o nosso caso, pois a segmentação residencial que utilizaremos não, necessariamente, corresponde às condições sociais homogêneas no espaço urbano metropolitano. Todavia, podemos perceber que, embora estas condições não sejam satisfeitas, há distinções importantes quando se considera a relação entre moradores da periferia metropolitana e o núcleo metropolitano, de um lado, e moradores de favela e moradores de não favela, de outro.

\section{METODOLOGIA}

O procedimento operacional para realização dos testes de hipóteses neste artigo consiste na realização de análise de dados secundários decorrentes de pesquisas domiciliares do tipo survey, construídas pelo Instituto Brasileiro de Geografia e Estatística (IBGE), que compõem a Pesquisa Nacional por Amostra de Domicílios (PNAD). A PNAD é uma pesquisa amostral que é levada a campo em todos os anos, com exceção daqueles nos quais ocorrem os censos demográficos. Desde seu surgimento, no final da década de 1960, ela não foi realizada somente em 1994, além dos anos em que os censos demográficos foram realizados, a saber: 1970, 1980, 1991, 2000 e 2010. Portanto, esta pesquisa possui uma série histórica anual de mais de quatro décadas, como poucas existentes no país.

A PNAD é uma pesquisa de abrangência nacional, sendo também representativa para todas as unidades da Federação (UF) e para nove regiões metropolitanas - Belém, Belo Horizonte, Curitiba, Fortaleza, 
Porto Alegre, Recife, Rio de Janeiro, Salvador e São Paulo. O Distrito Federal, apesar de ser uma unidade da Federação, também é classificado como região metropolitana. Por isso, quando fizermos referência ao conjunto das regiões metropolitanas estaremos considerando, além das nove regiões supracitadas, o Distrito Federal (ou Brasília). Os procedimentos analíticos efetuados neste artigo se referem ao conjunto das regiões metropolitanas, aqui denominado de Brasil Metropolitano, e à comparação entre elas.

O tipo de análise estatística que nos permitirá testar as hipóteses corresponde à análise de regressão linear múltipla, baseada no Método de Mínimos Quadrados Ordinários (MQO). A regressão linear múltipla nos possibilita testar o efeito conjugado de diversas variáveis, denominadas de variáveis independentes ou explicativas, sobre a variável dependente ou variável a ser explicada. A consideração necessária é que a variável dependente seja contínua, o que corresponde à característica do rendimento do trabalho principal dos indivíduos - a variável dependente deste artigo.

As análises realizadas neste artigo recorrem ao uso de métodos quantitativos referentes à análise de regressão contrastando três modelos analíticos: modelo de Mincer (teoria do capital humano); modelo credencialista; modelo da overeducation. O primeiro modelo consiste na utilização dos anos de escolaridade dos indivíduos e de uma variável proxy da experiência de trabalho para avaliar o nível de renda dos indivíduos. O segundo modelo incorpora no modelo anterior os níveis de escolaridade dos indivíduos, correspondente ao que poderíamos denominar de títulos ou credenciais educacionais. Esses dois primeiros modelos possibilitam realizar análise pelo lado da oferta do mercado de trabalho, pois focam nas características dos indivíduos. O terceiro modelo-overeducation - consiste na utilização de variáveis relativas aos anos de escolaridade requerida pela ocupação à situação de sobreeducação (overeducation) - quando os indivíduos possuem mais escolaridade que a ocupação exige - e à situação de subeducação (undereducation) - quando os indivíduos possuem menos escolaridade que a exigida pelas ocupações -, além de variável proxy da experiência de trabalho. Esse modelo focaliza o lado da demanda por trabalho.

Associadas às variáveis próprias de cada modelo analítico foram acrescentadas as variáveis referentes à posição social dos indivíduos e à segmentação residencial na metrópole, além das variáveis de contro- 
le (sexo e cor / raça), como pode ser visto no Quadro 1. A posição social dos indivíduos foi observada segundo um esquema de classes construído a partir da ocupação dos responsáveis pelos domicílios (Ribeiro e Ribeiro, 2013). A segmentação residencial na metrópole foi considerada em duas escalas: favela-não favela; núcleo-periferia ${ }^{2}$. A favela foi considerada como sendo os aglomerados subnormais existentes nas pesquisas domiciliares do IBGE. A periferia corresponde aos municípios metropolitanos com exceção do município núcleo principal, aquele que dá nome à região metropolitana. Foram consideradas apenas as pessoas de 25 a 59 anos de idade. A partir de 25 anos porque se procurou considerar as pessoas que, a rigor, já estariam em condições de possuir o nível superior de escolaridade; até 59 anos de idade porque nos-

\section{Quadro 1}

Variáveis do Modelo de Regressão

\begin{tabular}{|l|c|c|}
\hline Variáveis & Característica & Categoria de Referência \\
\hline Log renda/hora & Contínua & \\
Funos de escolaridade & Discreta & \\
Médio & Dummy & Superior \\
Escolaridade requerida & Dummy & Superior \\
Sobre-educação & Contínua & \\
Subeducação & Contínua & \\
Exp & Contínua & \\
Exp & Discreta & \\
Sexo: feminino & Discreta & Masculino \\
Cor: parda & Dummy & Branca \\
Cor: preta & Dummy & Branca \\
Dirigentes & Dummy & Drofissionais de Nível Superior \\
Peq. empregadores & Dummy & Profissionais de Nível Superior \\
Ocup. médias & Dummy & Profín \\
Trab. secundário & Dummy & Profissionais de Nível Superior \\
Oper. Constr. Civil & Dummy & Profissionais de Nível Superior \\
Trab. terc. espec. & Dummy & Profissionais de Nível Superior \\
Trab. terc. não espec. & Dummy & Profissionais de Nível Superior \\
Trab. agrícolas & Dummy & Profissionais de Nível Superior \\
Favela & Dummy & Profissionais de Nível Superior \\
Periferia & Dummy & Não favela \\
\hline
\end{tabular}

Fonte: Elaboração própria com base em PNAD/IBGE (1998, 2003 e 2009). 
sa preocupação foi considerar as pessoas que ainda não se encontram na idade de se aposentar, como são as mulheres de 60 anos ou mais. Para tanto, foram considerados os dados de 1998, 2003 e 2009 da PNAD/IBGE.

\section{ANÁLISE DOS RESULTADOS}

Na hipótese levantada neste artigo, discutimos que a segmentação residencial do território das metrópoles pode exercer efeito explicativo sobre os diferenciais de rendimento obtidos no mercado de trabalho entre os indivíduos. Assim, nosso objetivo é avaliar o efeito explicativo das duas dimensões da segmentação residencial do território que incorporamos à análise dos determinantes de renda, além de sua relação com a variável escolaridade que está sendo tratada de formas distintas, de acordo com os diferentes modelos analíticos utilizados. Diante disso, buscaremos discutir os mecanismos sociais decorrentes dos resultados apresentados.

O Quadro 2 apresenta o resultado do efeito explicativo de todas as variáveis independentes para o Brasil Metropolitano, nos anos de $1998^{3}$, 2003 e 2009. Nosso propósito aqui é focalizar nas variáveis referentes à segmentação residencial do território metropolitano. Porém, antes, é relevante apresentar, mesmo que de modo sucinto, os retornos decorrentes da escolaridade nos três modelos analíticos utilizados, inclusive para explicar as diferenças das interpretações de cada um deles.

Podemos observar que o retorno da escolaridade no modelo 1 (teoria do capital humano), controlado por todas as demais variáveis, explica, em 1998, 9,5\%, ou seja, a cada ano a mais de escolaridade os indivíduos ganham, em média, 9,5\% mais. Porém, há redução desses retornos ao longo do tempo, como podemos observar em 2003 (retornos de 8,9\%) e em 2009 de $7,7 \%$.

No modelo 2 (credencialista), que incorpora as variáveis referentes à credencial educacional, observamos que as pessoas que possuem nível fundamental e médio ganham, em média, menos que as pessoas com nível superior, o que comprova que o título educacional importa como explicação dos retornos monetários, para além dos anos de escolaridade.

Também podemos observar que os retornos da escolaridade requerida (modelo 3), nos anos analisados, são maiores que os retornos da escolaridade adquirida (modelo 1), o que demonstra que mais importante 
que a escolaridade dos indivíduos é a escolaridade requerida pelo mercado de trabalho. Além disso, observamos no modelo 3 que há um maior prêmio pela sobre-educação, em módulos, que a penalidade pela subeducação. Mas o prêmio pela sobre-educação é inferior aos retornos da escolaridade requerida, que está de acordo com evidências encontradas em outros estudos (Hartog, 2000; Diaz e Machado, 2008). Isso nos possibilita concluir que os indivíduos sobre-educados auferem, em média, maior rendimento que os indivíduos que estão na mesma ocupação, mas com escolaridade compatível. Porém, esses mesmos indivíduos sobre-educados obtêm, em média, menor rendimento que aqueles que possuíam a mesma escolaridade, mas que estavam em ocupações condizentes com sua exigência.

Em relação à segmentação residencial do território metropolitano, observados na dupla escala de análise - favela/não favela e periferia/núcleo -, podemos observar que em todos os modelos analíticos utilizados os resultados mostram-se significativos ${ }^{4}$. Isso quer dizer que há diferenças nos retornos de rendimento do trabalho entre os indivíduos que moram em favela em relação aos que moram em não favela e dos indivíduos que moram na periferia em relação aos que moram no núcleo.

Ao considerar os modelos 1 e 2, observamos que os moradores de favela possuem retornos menores (explicado pelo sinal negativo) que os moradores de não favela, mesmo em comparação a indivíduos que possuem as mesmas características pessoais, como escolaridade, experiência de trabalho, sexo, cor e posição social. A mesma leitura é válida para os moradores da periferia em relação aos do núcleo metropolitano. Os moradores da periferia estão em desvantagem mesmo considerando que possuem as mesmas características pessoais.

Também considerando o modelo 3, que foca a demanda por trabalho, observamos que estão em desvantagem os indivíduos que moram em favela em relação aos que moram em não favela e os indivíduos que moram na periferia em relação aos que moram nos núcleos, o que quer dizer que há discriminação dos indivíduos no mercado de trabalho pelos retornos monetários explicada por seu local de moradia.

Em todos os modelos podemos observar que há redução do efeito explicativo da variável favela ao longo do tempo. Isso quer dizer que as diferenças de retornos dos rendimentos entre morador de favela e morador de não favela têm, em média, diminuído. Em 1998, os moradores 
Território e Desigualdades de Renda em Regiões Metropolitanas do Brasil

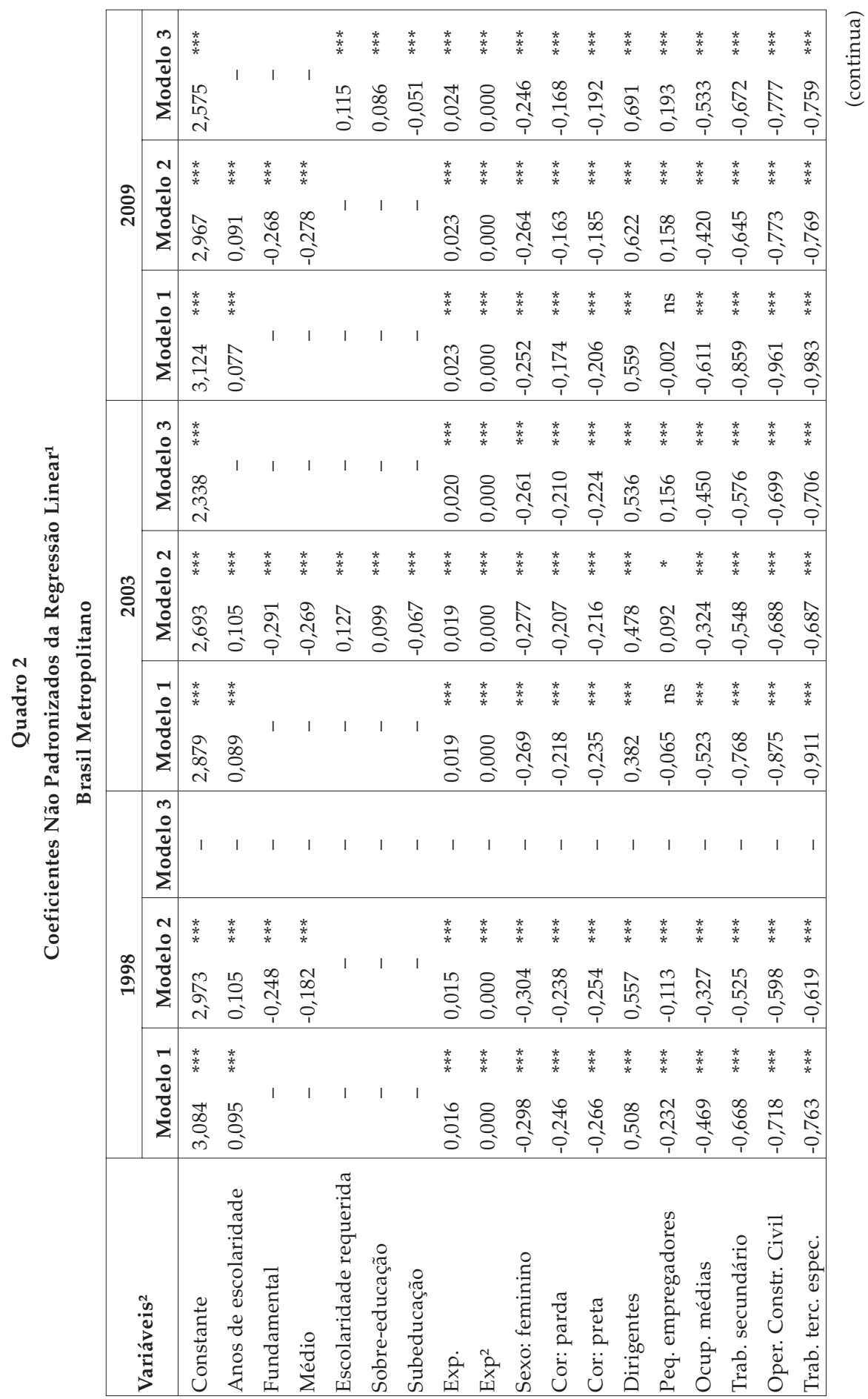

DADOS - Revista de Ciências Sociais, Rio de Janeiro, vol. 58, $\mathrm{n}^{0}$ 4, 2015 


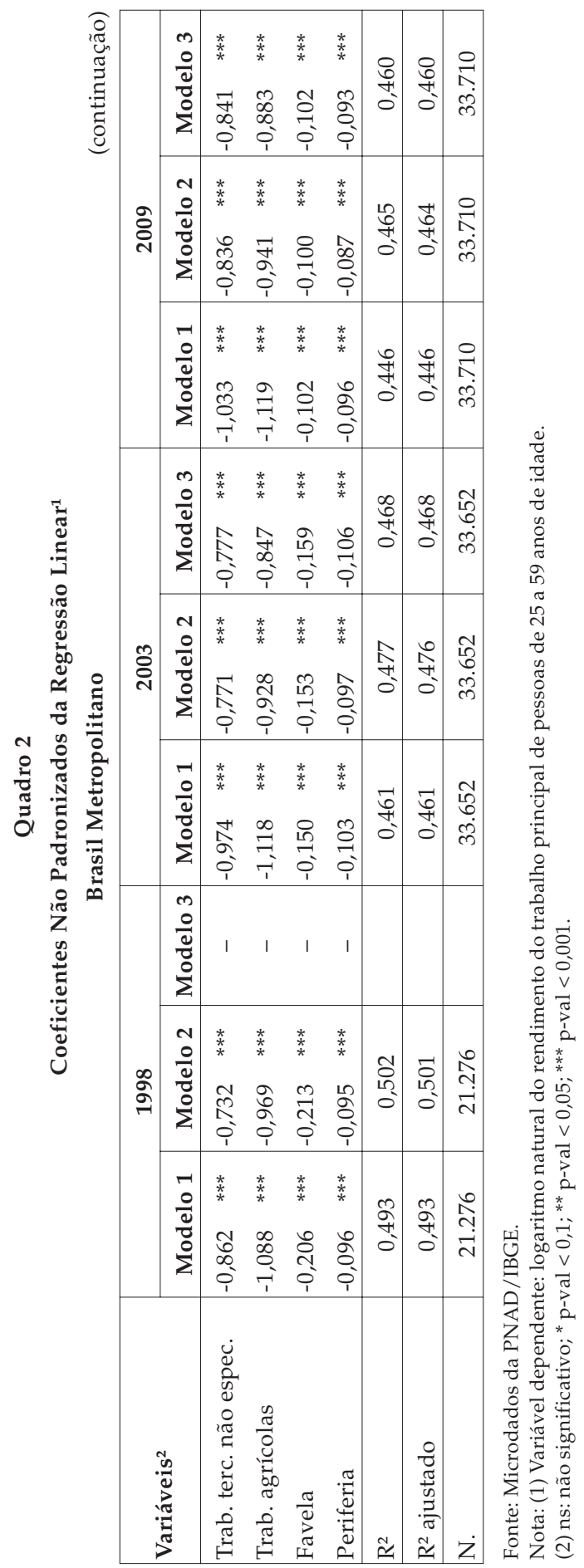

932 DADOS - Revista de Ciências Sociais, Rio de Janeiro, vol. 58, no 4, 2015 
de favela ganhavam, em média, menos $20 \%$ que os moradores de não favela. Em 2009, passaram a ganhar, em média, menos 10\% em comparação aos moradores de não favela. Esse comportamento, porém, não é observado entre os moradores da periferia e do núcleo metropolitano, em que as diferenças de retornos monetários são mais persistentes ao longo do tempo, em torno de $10 \%$ em todos os anos.

Para comparar o efeito explicativo da segmentação residencial do território entre as regiões metropolitanas utilizadas neste artigo, podemos observar os resultados no Quadro 3, tanto para os retornos decorrentes de morar em favela em relação a morar em não favela, quanto para os retornos de morar em periferia em relação a morar no núcleo metropolitano, para os anos de 1998 e 2009. É importante ressaltar que, apesar de apresentadas apenas as variáveis referentes à segmentação residencial do território metropolitano, esses resultados estão sendo controlados por todas as demais variáveis inseridas nos modelos, conforme demonstrado no Quadro 1, descritivo das variáveis.

Quando observamos os retornos de morar em favela, percebemos que apenas nas regiões metropolitanas do Rio de Janeiro e de São Paulo os resultados são estatisticamente significativos ao nível de 1\%, em todos os anos e em todos os modelos analíticos. A região metropolitana de Porto Alegre também apresenta retornos estatisticamente significativos ao nível de $5 \%$ para todos os anos e em todos os modelos. As demais regiões metropolitanas não mostram comportamento homogêneo ao longo do tempo e entre os modelos analíticos, o que nos leva a considerar a importância dessa escala de análise, sobretudo, para as regiões metropolitanas de São Paulo e do Rio de Janeiro.

Em relação aos retornos decorrentes de morar na periferia em relação a morar no núcleo metropolitano, observamos também que os resultados se apresentaram estatisticamente significativos para seis regiões metropolitanas, em todos os anos e em todos os modelos: Fortaleza, Belo Horizonte, Rio de Janeiro, São Paulo, Curitiba e Porto Alegre. Esse resultado sugere que a segmentação residencial observada pela relação núcleo-periferia ajuda a explicar as diferenças de obtenção de renda entre os indivíduos no mercado de trabalho, no sentido de que os indivíduos moradores de periferia, na maior parte das regiões metropolitanas, ganham, em média, menos que os moradores do núcleo metropolitano. Isso, por sua vez, nos leva à consideração da importância 


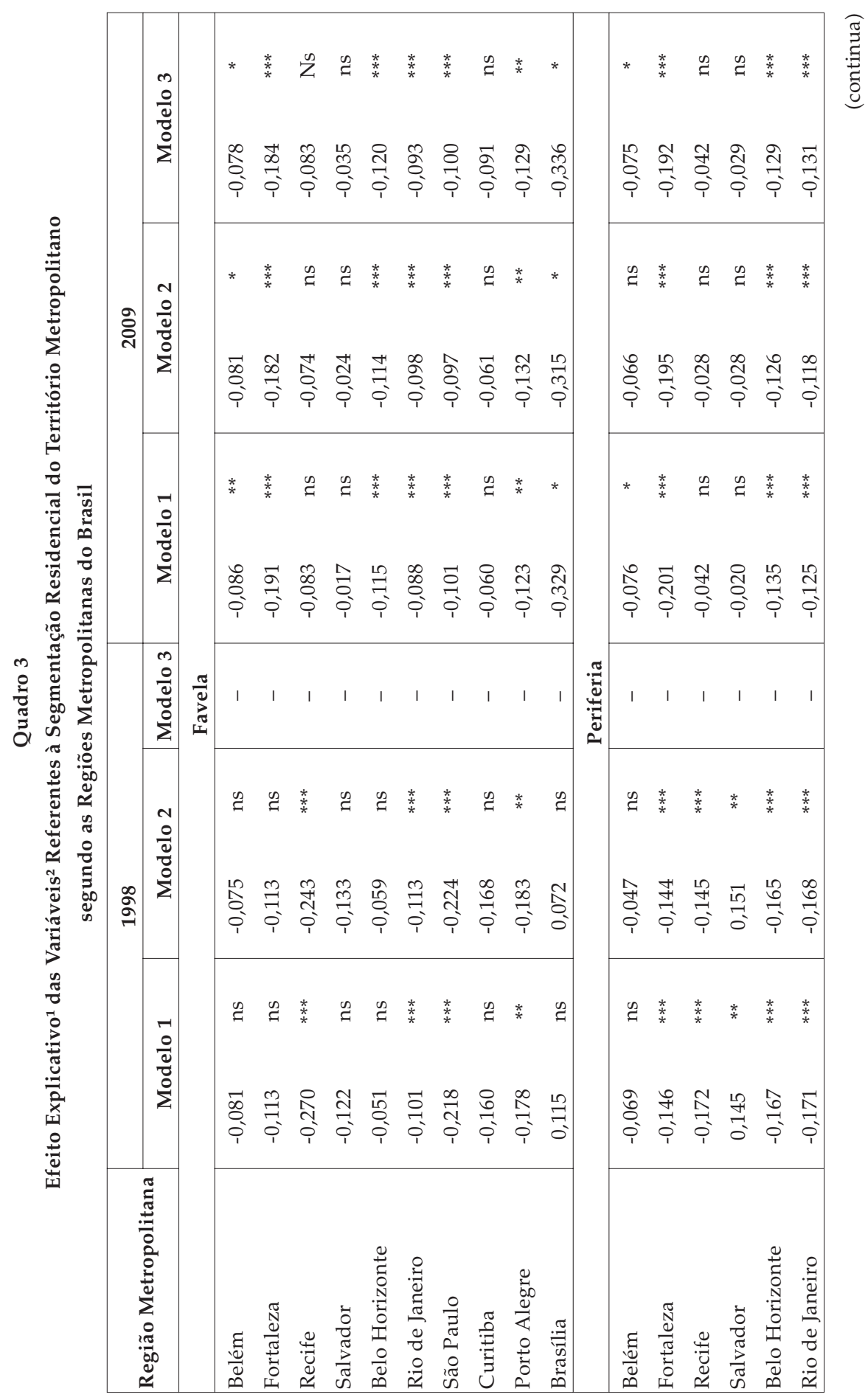

934 DADOS - Revista de Ciências Sociais, Rio de Janeiro, vol. 58, nำ 4, 2015 
Território e Desigualdades de Renda em Regiões Metropolitanas do Brasil

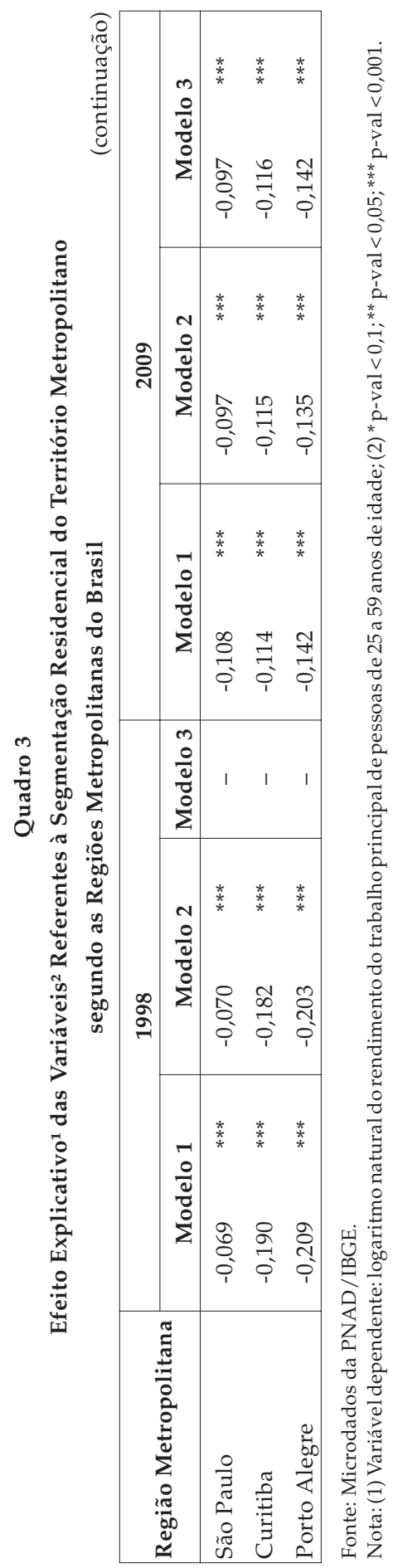


dessa escala espacial para compreensão das desigualdades de oportunidades do mercado de trabalho.

Em todos os modelos analíticos que testamos, podemos perceber que a segmentação residencial do território metropolitano contribui para a explicação das diferenças de obtenção de rendimento do trabalho, seja entre moradores de favela e de não favela, seja entre moradores da periferia metropolitana e do núcleo metropolitano. Apesar disso, observamos que as pequenas diferenças na obtenção de rendimento, verificadas pela segmentação residencial do território metropolitano, apresentam efeitos estatisticamente significativos para o conjunto das regiões metropolitanas.

A desvantagem na obtenção de rendimentos dos moradores de favela e da periferia metropolitana em relação, respectivamente, aos moradores de não favela e do núcleo metropolitano pode ser decorrente de mecanismos diferentes, tendo em vista o modo como se organiza socialmente o território metropolitano no Brasil.

De modo geral, as favelas brasileiras concentram-se no município núcleo das regiões metropolitanas, onde também está concentrada boa parte dos empregos, sobretudo, os de melhores remunerações (Ribeiro, Rodrigues e Corrêa, 2009). Neste caso, podemos observar que os moradores de favela estão fisicamente próximos do mercado de trabalho, apesar de sua desvantagem ser decorrente de sua distância social, pois, como se sabe, os moradores de favela, em geral, apresentam condições socialmente desvalorizadas em relação aos moradores de não favela.

Portanto, se há desvantagem entre os moradores de favela em relação aos moradores de não favela na obtenção de rendimento no mercado de trabalho, os mecanismos que favorecem essas diferenças são carregados de efeitos simbólicos de desvalorização social, utilizando-se as características dos moradores e de suas condições de moradia como signo, associado às condições sociais dos moradores de favela, que caracterizam o modo como se apresenta a segregação residencial nas metrópoles brasileiras. Assim, é possível que estejam operando conjuntamente dois mecanismos: discriminação e isolamento de redes sociais. A discriminação decorreria do estigma que os demandantes de trabalho teriam em relação aos moradores de favela. Neste caso, a favela pode ser compreendida como um tropo social, na medida em que seria usada para descredenciar aqueles que nela moram, não obstante seus 
atributos pessoais como a escolaridade. $\mathrm{O}$ isolamento de redes sociais decorreria da não interação social com grupos que ocupam posições mais elevadas na estrutura social, dificultando a possibilidade de obtenção de empregos de maior remuneração no mercado de trabalho.

Por outro lado, os mecanismos que deixam os moradores da periferia metropolitana em desvantagem na obtenção de rendimentos em relação aos moradores do núcleo podem ser decorrentes não necessariamente da forma como se apresenta a segregação residencial nas metrópoles brasileiras, mas da maneira como se apresenta a segmentação residencial, por um lado, e a localização de empregos na metrópole, por outro. Como o mercado de trabalho tende a concentrar parcela significativa dos empregos no núcleo metropolitano, sobretudo, os empregos de maior remuneração, e a periferia normalmente concentra parcela expressiva da população de condição social mais precária, são dois os mecanismos que podem explicar as desvantagens dos moradores da periferia na obtenção de rendimento: distância física e redes sociais.

A distância do local de concentração de empregos torna mais difícil para os moradores da periferia a procura por emprego, sobretudo aqueles de maior remuneração. Essa dificuldade é decorrente, por um lado, da acessibilidade dos indivíduos associada às precárias condições de mobilidade urbana nas metrópoles brasileiras e, por outro, pelo constrangimento imposto pelo preço do deslocamento.

Diferente dos moradores de favela, que normalmente estão próximos do mercado de trabalho, as dificuldades de inserção dos moradores em redes sociais que poderiam colaborar para obtenção de informação sobre empregos de maior remuneração, por exemplo, são decorrentes da distância física que os grupos sociais da periferia possuem em relação àqueles que se localizam no núcleo metropolitano. Ou seja, neste caso, a segmentação residencial torna difícil o estabelecimento de vínculos sociais mais amplos e heterogêneos entre os moradores da periferia e do núcleo metropolitano. Mesmo que na sociedade contemporânea o uso das tecnologias da comunicação e informação esteja mais disseminado, o que poderia facilitar o estabelecimento de vínculos sociais à distância física, essa não é uma realidade do conjunto da região metropolitana. Há ainda uma grande desigualdade de posse de microcomputador entre os domicílios de acordo com sua localização no territó- 
rio metropolitano, estando mais desfavorecidos aqueles que moram na periferia ou em favela (Ribeiro et al., 2013).

Podemos supor, todavia, que, tanto na situação da favela quanto da periferia metropolitana, os recursos institucionais são de pior qualidade que os existentes seja na não favela seja no núcleo metropolitano. Neste sentido, além das dificuldades já apontadas que colocam em desvantagem os moradores de favela e de periferia, a superação dessas desvantagens exige esforço redobrado para os indivíduos que se localizam nesses contextos territoriais, na medida em que os recursos que poderiam contrabalançar as desigualdades territoriais decorrentes dos outros mecanismos apontados anteriormente colaboram para reforçar ainda mais essas desigualdades.

Essa análise do conjunto das regiões metropolitanas, todavia, esconde as diferenças existentes entre elas no que se refere ao efeito explicativo da segmentação residencial do território metropolitano sobre os diferenciais de rendimento do trabalho, tanto em relação à análise da microescala quanto à análise da macroescala. Ao considerar a importância dessas escalas analíticas na comparação entre as regiões metropolitanas, constatamos que somente no Rio de Janeiro e em São Paulo as duas escalas apresentam efeitos explicativos significativos para todos os anos analisados. Ou seja, somente nas regiões metropolitanas do Rio de Janeiro e de São Paulo o efeito explicativo da relação entre favela e não favela e da relação entre periferia e núcleo metropolitano se demonstrou significativo ao nível de $1 \%$ em todos os anos analisados. E isso se apresentou para todos os modelos analíticos testados.

Nesse sentido, podemos considerar a importância de contrastar as duas escalas para análise dos diferenciais de rendimento do trabalho relevante apenas nessas duas regiões metropolitanas - Rio de Janeiro e São Paulo -, que são, aliás, as principais metrópoles brasileiras, onde há as maiores concentrações populacionais e também onde a estrutura econômica é mais complexa e, por conseguinte, é mais complexo também o mercado de trabalho. Além disso, podemos dizer que, por diversas razões, são as metrópoles que expressam o modelo urbano brasileiro de dupla distância (Ribeiro e Koslinski, 2009): o Rio de Janeiro como consequência da sua própria formação histórica; São Paulo, em razão de na década de 1980 ter havido uma explosão de favelas no seu principal município, sobretudo em suas áreas centrais. 


\section{COMENTÁRIOS FINAIS}

Vimos que, ao considerar o conjunto das regiões metropolitanas, a dupla escala de análise da segmentação residencial do território metropolitano se mostrou importante para gerar elementos empíricos que nos permitissem construir hipóteses sobre os mecanismos que explicam as diferenças entre os indivíduos na obtenção de rendimento do trabalho. Vimos também na microescala, ao considerar a comparação entre as regiões metropolitanas, que somente no Rio de Janeiro e em São Paulo constatamos diferenças, entre favela e não favela, relevantes na análise dos rendimentos do trabalho. Porém, na macroescala observamos importância das diferenças entre núcleo e periferia na explicação dos diferenciais de rendimento nas regiões metropolitanas de Fortaleza, Belo Horizonte, Rio de Janeiro, São Paulo, Curitiba e Porto Alegre. Diante desses resultados encontrados, surge o questionamento sobre a importância da escala para as análises do "efeito território".

Questionamentos como esses - e outros referentes à construção de modelos analíticos do efeito território - têm sido realizados por diversos pesquisadores na perspectiva de aperfeiçoamento dos modelos de análise empírica e de construção de hipóteses explicativas sobre seus mecanismos, o que justifica nosso interesse na reflexão dos procedimentos metodológicos para além dos próprios resultados empíricos encontrados. Nesse sentido, torna-se relevante levarmos alguns desses questionamentos em consideração para uma melhor interpretação do efeito território. Além disso, vale destacar que esse tipo de abordagem relativa ao efeito território tende a ganhar maior relevância porque, cada vez mais, os seres humanos vivem em sociedades urbanas, na medida em que o urbano tem enorme importância na reprodução das relações sociais (Lefebvre, 1999).

Roger Andersson e Sako Musterd (2010) realizaram um estudo de três áreas metropolitanas da Suécia para analisar qual escala é mais apropriada para análise do efeito território, de modo a colaborar para o campo disciplinar dos estudos urbanos que tem cada vez mais se desenvolvido nas últimas décadas referente ao neighborhood effects, mas que ainda apresenta muitas limitações ou mesmo questões metodológicas ainda sem consenso. Nesse estudo, os autores compararam três escalas territoriais para analisar qual dessas escalas seria mais adequada para compreensão das diferentes posições de renda entre os indivíduos. A partir da definição geográfica de escala, em que o nível mais 
elevado era a escala dos municípios que compõem as áreas metropolitanas, os autores testaram os seus efeitos, para o ano de 2002, utilizando-se de quatro variáveis de contexto - a porcentagem de desempregados em 1999, a porcentagem de não migrantes em 1999, a porcentagem com renda nos três últimos decis de renda em 1999 e a porcentagem com renda nos três primeiros decis de renda neste mesmo ano. Para tanto, realizaram uma análise de regressão multinível, na perspectiva de separar os efeitos decorrentes dos indivíduos, propriamente dito, dos efeitos decorrentes do contexto em que estão inseridos. Os resultados encontrados por Andersson e Musterd demonstram que os efeitos da escala do município, que corresponde ao maior nível, foram os mais fracos, atestando que as escalas de menor nível espacial exercem maior influência sobre as chances dos indivíduos.

Pela limitação imposta decorrente do tipo de dados utilizados na análise deste trabalho sobre o efeito da segmentação residencial do território metropolitano - que se utilizou da PNAD -, o recorte territorial empregado, em que, de um lado, separou a favela do conjunto da região metropolitana e, de outro, separou o núcleo metropolitano da periferia metropolitana, apesar de expressar escalas diferentes, não chegou a ser um recorte escalar de nível significativo para testar o efeito territorial sobre as chances dos indivíduos no mercado de trabalho - o efeito de contexto social relevante para os indivíduos, para sua socialização, para sua relação com a sociedade. Nesse sentido, podemos afirmar que o efeito da segmentação residencial do território metropolitano poderia ser mais expressivo se fosse possível realizar um recorte escalar num nível menor. A importância do território na análise das desigualdades de renda seria ainda maior que a observada pelos resultados estatísticos encontrados e analisados. Assim, sugerimos que estudos que procuram analisar o efeito da segmentação residencial do território metropolitano utilizem de base de dados capaz de apreender escalas espaciais como a do bairro ou da vizinhança.

Todavia, temos que considerar também a dificuldade de definição do que seja a vizinhança. Como Small e Newman (2001) salientaram, essa definição pode ser feita de diversas maneiras, podendo compreender a vizinhança como espaço social, como conjunto de relacionamentos, como conjunto de instituições existentes, ou ainda como unidade simbólica. Mas, qualquer que seja a definição, sua operacionalização para os estudos que se preocupam em compreender as desvantagens sociais será limitada pela base de dados utilizada. 
No nosso caso, a definição da segmentação residencial do território metropolitano decorreu apenas de sua definição geográfica, sem compreender nessa definição variáveis de contexto. Contudo, essa definição geográfica, que também decorreu dos limites da base de dados utilizada, se apoiou na literatura que demonstra como a estrutura social se expressa nas diferentes condições de vida dos moradores de favela e dos moradores de não favela, por um lado, e dos moradores do núcleo e dos moradores da periferia, por outro. Porém, a literatura que faz referência à periferia não a compreende, tão somente, a partir dos municípios metropolitanos que não seja o município núcleo. Ao contrário, dentro do próprio município núcleo podem existir bairros de periferia. Se os dados possibilitassem observar essas diferenças, possivelmente os resultados do efeito da segmentação residencial do território metropolitano seriam mais expressivos do que foi demonstrado aqui.

A análise que empreendemos sobre a segmentação residencial do território metropolitano se utilizou da concepção de neighborhood effect, elaborado a partir dos estudos urbanos realizados nos Estados Unidos da América desde os anos 1980 (Wilson, 1987). Apesar da utilização dessa concepção para as análises realizadas neste artigo, tivemos a preocupação de operacionalizá-lo a partir da compreensão do modo particular de constituição das metrópoles brasileiras, em que se definiu ao longo do tempo um modo específico de segmentação residencial, expressão também da segregação socioespacial, que se caracteriza pela dupla escala: de um lado, a distância social e a proximidade física (favela e não favela) e, de outro, a distância física e a distância social (núcleo e periferia) (Ribeiro e Koslinski, 2009).

Porém, como observou Wacquant (2001), ao comparar o gueto norte-americano e a banlieu francesa, a transposição de categorias que foram construídas espacial e historicamente em outros lugares, corre-se o risco de transposição também de outras realidades. Essa observação leva-nos também a questionar o significado das categorias que traduzem a particularidade da segmentação residencial para todas as regiões metropolitanas.

A favela, que é uma das expressões de desigualdades sociais e territoriais das metrópoles brasileiras - uma das formas de reconhecimento coletivo da distinção social; designa uma desigualdade que vai além das diferenças de condições de vida e dos atributos dos indivíduos -, não é uma realidade de todas as regiões metropolitanas, ao mesmo 
tempo que as relações que se dão entre moradores de favela e moradores de não favela podem não ser as mesmas naquelas regiões metropolitanas onde elas existem. Como vimos, as regiões metropolitanas que, de fato, expressam diferenças nas chances dos indivíduos no mercado de trabalho na análise sobre as favelas são as regiões metropolitanas do Rio de Janeiro e de São Paulo. Foi nessas regiões metropolitanas que se conformou um modo particular da morfologia urbana, em que as favelas ganharam expressão quantitativa e qualitativa, no sentido de que elas se constituíram socialmente, servindo como representação coletiva da segregação socioespacial das metrópoles brasileiras.

A periferia, por outro lado, é uma categoria social que também expressa a segmentação residencial das metrópoles brasileiras. Mesmo que o conteúdo que antes essa categoria incorporava tenha se modificado (o que se coloca para nós como um questionamento), é uma categoria que consegue expressar as desigualdades sociais manifestadas no território metropolitano para um conjunto mais amplo de regiões metropolitanas. Porém, embora possamos analisar boa parte das metrópoles brasileiras segundo essa concepção, é importante considerar que em algumas regiões metropolitanas essa dicotomia núcleo-periferia não é diretamente observável, na medida em que as condições sociais tanto dos moradores do "núcleo" quanto dos moradores da "periferia" são mais homogêneas, apesar de serem condições homogêneas precárias, como são ainda algumas regiões metropolitanas do Norte e do Nordeste. Isso também pode significar que o que compreendemos como núcleo se realiza em uma escala muito diferente do que conseguimos apreender, demonstrando que os processos e as escalas são diferentes entre as regiões metropolitanas. Mas que, de todo modo, nos possibilita interrogar sobre a transposição de realidades quando transportamos categorias, mesmo que nos limites da fronteira nacional.

Nesse sentido, compreendemos que nosso estudo acrescenta ao debate do efeito território sobre as oportunidades relativas ao mercado de trabalho a importância da escala espacial de análise, uma vez que ela pode apresentar efeitos distintos nos contextos metropolitanos, como vimos nos diferentes efeitos favela-não favela e núcleo-periferia. Isso é relevante para a compreensão dos mecanismos que operam em cada nível territorial de modo a pensar em alternativas de superação das desigualdades sociais que se viabilizam por meio do território.

Destaca-se, todavia, que este artigo avança na análise do efeito territorial quando considera três modelos analíticos para sua operacionaliza- 
ção: dois modelos que focalizam o efeito território visto pelas características da oferta de trabalho (Mincer e Credencialismo), pois apresentam os atributos de escolaridade dos indivíduos; um modelo que apresenta o efeito da escolaridade exigida pelas ocupações, portanto relativo à demanda por trabalho (overeducation). Em todos eles pudemos observar a importância do território para compreensão das desigualdades de renda no mercado de trabalho. Isso comprova, a nosso ver, que, mesmo havendo mudanças no efeito da escolaridade quando se contrapõem os três modelos analíticos, o território continua exercendo explicação sobre as desigualdades de obtenção de renda no mercado de trabalho, o que nos informa que seu efeito independe, pelo menos diretamente, das demais variáveis. E se o território, independente dos atributos apresentados pelos indivíduos ou dos atributos exigidos deles, exerce efeito sobre a explicação das desigualdades existentes no mercado de trabalho, o campo analítico relativo ao mundo do trabalho deve considerar, cada vez mais, as contribuições da sociologia urbana para ampliar sua compreensão dos mecanismos geradores de desigualdades.

(Recebido para publicação em janeiro de 2014)

(Reapresentado em fevereiro de 2015)

(Aprovado para publicação em março de 2015) 


\section{Marcelo Gomes Ribeiro}

\section{NOTAS}

1. Ver Flores (2008), que procurou relacionar o aporte teórico do efeito vizinhança com o aporte relacionado à estrutura de oportunidades para analisar os resultados na educação para crianças em distintos bairros da cidade de Santiago do Chile. Suárez e Groisman (2008) também procuram analisar o efeito do contexto social de vizinhança sobre a escolaridade e o rendimento educacional de crianças para o conglomerado da grande Buenos Aires. Solis (2008) procurou analisar a relação entre o nível socioeconômico da vizinhança (efeito vizinhança) e a probabilidade da continuidade escolar entre a educação secundária e o bacharelado (curso superior). Alves, Franco Júnior e Ribeiro (2008) buscaram analisar o efeito de vizinhança sobre o risco de distorção idade-série para crianças e adolescentes da cidade do Rio de Janeiro. Outros estudos deram continuidade a esse tipo de abordagem, como o de Salata (2010); Salata e Sant'Anna (2010); Ribeiro, Rodrigues e Côrrea (2009); Ribeiro et al. (2009).

2. Neste artigo vamos nos concentrar na análise conjunta de todas as variáveis, procurando focalizar nos resultados referentes à segmentação residencial do território metropolitano segundo a dupla escala de análise: favela e periferia. Para uma análise mais pormenorizada do efeito das variáveis referentes à escolaridade e, em acréscimo, do efeito das variáveis referentes à posição social, consultar Salata (2010), onde esses efeitos são testados e discutidos em detalhe.

3. Não foi possível construir as variáveis do modelo 3 (overeducation) para o ano de 1998, porque não havia os dados necessários para os anos anteriores a 2001.

4. A possibilidade de os resultados se mostrarem significativos nas análises de regressão feitas a partir do uso dos microdados da PNAD decorre da operacionalização do peso de expansão das variáveis. Essa operacionalização consiste no cálculo da fração amostral multiplicado pelo peso original da base de dados. A fração amostral corresponde, por sua vez, à razão entre o número de indivíduos sem peso e o número de indivíduos com o peso de expansão. Essa operacionalização não altera o resultado dos coeficientes, tampouco do coeficiente de determinação $\left(R^{2}\right)$. 


\section{REFERÊNCIAS BIBLIOGRÁFICAS}

ALVES, Fátima; FRANCO JÚNIOR, Creso; RIBEIRO, Luiz Cesar Q. (2008), “Segregação Residencial e Desigualdade Escolar no Rio de Janeiro", in L. C. Q. Ribeiro; R. Kaztman (orgs.), A Cidade Contra a Escola? Segregação Urbana e Desigualdades Educacionais em Grandes Cidades da América Latina. Rio de Janeiro, Letra Capital, pp. 91-118.

ANDERSSON, Roger; MUSTERD, Sako. (2010), “What Scale Matters? Exploring the Relationships between Individuals' Social Position, Neighbourhood Context and the Scale of Neighbourhood". Geografiska Annaler: Series B, Human Geography, vol. 92, no 1, pp. 23-43.

ARANTES, Pedro Fiori. (2009), "Em Busca do Urbano. Marxistas e a Cidade de São Paulo nos Anos de 1970". Novos Estudos, no 83, pp. 103-127.

BARBOSA FILHO, Fernando de H.; PESSÔA, Samuel. (2009), “Retorno da Educação no Brasil". Pesquisa e Planejamento Econômico, vol. 38, no 1, pp. 97-125.

BARROS, Ricardo Paes de; FRANCO, Samuel; MENDONÇA, Rosane. (2007), “A Recente Queda da Desigualdade de Renda e o Acelerado Progresso Educacional Brasileiro da Última Década". Texto para Discussão, no 1304, Ipea, pp. 1-39.

BOURDIEU, Pierre. (1997), “Efeitos do Lugar”, in P. Bourdieu (org.), A Miséria do Mundo. Petrópolis, RJ, Vozes, pp. 159-166.

. (2007), "Reprodução Cultural e Reprodução Social”, in S. Miceli (org.), A Economia das Trocas Simbólicas (introdução, organização e seleção de S. Miceli). São Paulo, Perspectiva, pp. 295-336.

COLLINS, Randall. (1971), “Functional and Conflict Theories of Educational Stratification". American Sociological Review, vol. 36, no 6, pp. 1002-1019.

DIAZ, Maria Dolores Montoya; MACHADO, Luciano. (2008), “Overeducation e Undereducation no Brasil”. Estudos Econômicos, vol. 38, no 3, pp. 431-460.

DUNCAN, Greg J.; HOFFMAN, Saul D. (1981), "The Incidence and Wage Effects of Overeducation". Economics of Education Review, vol. 1, no 1, pp. 75-86.

ELLEN, Ingrid Gould; TURNER, Margery Austin. (1997), “Does Neighborhood Matter? Assessing Recent Evidence". Housing Policy Debate, vol. 8, no 4, pp. 833-866.

FLORES, Carolina. (2008), "Segregação Residencial e Resultados Educacionais na Cidade de Santiago do Chile", in L. C. Q. Ribeiro; R. Kaztman (orgs.), A Cidade Contra a Escola? Segregação Urbana e Desigualdades Educacionais em Grandes Cidades da América Latina. Rio de Janeiro, Letra Capital, pp. 145-179.

GUIMARÃES, Nadya A.; CARDOSO, Adalberto. (2008), "Apresentação", in N. A. Guimarães et al. (orgs.), Mercados de Trabalho e Oportunidades: Reestruturação Econômica, Mudança Ocupacional e Desigualdade na Inglaterra e no Brasil. Rio de Janeiro, FGV Editora, pp. 7-18.

HARVEY, David. (1980), A Justiça Social e a Cidade. São Paulo, Hucitec.

HARTOG, Joop. (2000), “Over-education and Earnings: Where Are We, Where should We Go?" Economics of Education Review, no 19, pp. 131-147. 


\section{Marcelo Gomes Ribeiro}

KAZTMAN, Rubén. (2001), “Seducidos y Abandonados: El Aislamiento Social de los Pobres Urbanos". Revista de La Cepal, vol. 75, pp.171-188.

(org.), (1999), Activos y Estructuras de Oportunidades. Estudios sobre las Raíces de la Vulnerabilidad Social en Uruguay. Montevideo, CEPAL/PNUD.

KOWARICK, Lucio. (1979), A Espoliação Urbana. São Paulo, Paz e Terra.

LEFEBVRE, Henri. (1999), A Revolução Urbana. Belo Horizonte, UFMG Editora.

MINCER, Jacob A. (1974), Schooling, Experience, and Earnings. New York, Columbia University Press.

PERLMAN, Janice. (1977), O Mito da Marginalidade: Favelas e Política no Rio de Janeiro. Rio de Janeiro, Paz e Terra.

RIBEIRO, Luiz Cesar de Q. (2008), “Proximidade Territorial e Distância Social: Reflexões sobre o Efeito do Lugar a partir de um Enclave Urbano". Revista VeraCidade, vol. 3, no 3, pp. 1-21.

; KAZTMAN, Rubén (orgs.). (2008), A Cidade Contra a Escola? Segregação Urbana e Desigualdades Educacionais em Grandes Cidades da América Latina. Rio de Janeiro, Letra Capital, pp. 223-244.

RIBEIRO, Luiz Cesar de Q.; KOSLINSKI, Mariane Campello. (2009), “A Cidade contra a Escola? O Caso do Município do Rio de Janeiro", in Anais do XIV Congresso Brasileiro de Sociologia. Rio de Janeiro, Sociedade Brasileira de Sociologia, 28-31 de julho.

RIBEIRO, Luiz Cesar de Q.; RODRIGUES, Juciano Martins; CORRÊA, Filipe Souza. (2009), Segregação Residencial e Mercado de Trabalho nos Grandes Espaços Urbanos Brasileiros. Rio de Janeiro, Observatório das Metrópoles/ IPPUR/FASE, pp. 1-62.

RIBEIRO, Luiz Cesar de Q. et al. (2013), “Desigualdades Digitais: Acesso e Uso da Internet, Posição Social e Segmentação Espacial nas Metrópoles Brasileiras". Análise Social, vol. XLVIII, no 207, pp. 288-320.

RIBEIRO, Marcelo G. et al. (2009), "Segregação Residencial nas Metrópoles e Desigualdade no Mercado de Trabalho: Cor/Raça e Escolaridade", in Anais do XIV Congresso Brasileiro de Sociologia. Rio de Janeiro, Sociedade Brasileira de Sociologia, 28-31 de julho.

RIBEIRO, Marcelo G.; RIBEIRO, Luiz Cesar de Q. (2013), Análise Social do Território: Fundamentos Teóricos e Metodológicos. Rio de Janeiro, Letra Capital.

SALATA, André Ricardo. (2010), Estudar X Trabalhar: As Influências do Local de Moradia sobre as Escolhas dos Jovens no Município do Rio de Janeiro. Dissertação (Mestrado em Sociologia e Antropologia), Programa de Pós-Graduação em Sociologia e Antropologia, Universidade Federal do Rio de Janeiro, Rio de Janeiro.

; SANT’ANNA, Maria Josefina G. (2010), “Entre o Mercado de Trabalho e a Escola: Os Jovens no Rio de Janeiro", in L. C. de Q. Ribeiro et al. (orgs.), Desigualdades Urbanas, Desigualdades Escolares. Rio de Janeiro, Letra Capital/Observatório das Metrópoles, IPPUR/UFRJ, pp. 91-120.

SCHULTZ, Theodore W. (1961), "Investment in Human Capital". American Economic Review, vol. 51, o 1, pp. 1-17. 
SILVA, Luiz Antônio Machado da. (2011) [1967], “A Política na Favela”. DILEMAS: Revista de Estudos de Conflito e Controle Social, vol. 4, no 4, pp. 699-716.

SMALL, Mario Luis; NEWMAN, Katherine. (2001), "Urban Poverty after the Truly Disadvantaged: The Rediscovery of the Family, the Neighborhood, and Culture". Annual Review of Sociology, vol. 27, pp. 23-45.

SOLIS, Patrício. (2008), "Efeitos do Nível Socioeconômico da Vizinhança na Continuidade Escolar entre o Ensino Médio e o Pré-universitário no México, Distrito Federal". in L. C. Q. Ribeiro; R. Kaztman (orgs.), A Cidade Contra a Escola? Segregação Urbana e Desigualdades Educacionais em Grandes Cidades da América Latina. Rio de Janeiro, Letra Capital, pp. 223-244.

SUÁREZ, Ana Lourdes; GROISMAN, Fernando. (2008), “Segregação Residencial e Conquistas Educacionais na Argentina", in L. C. de Q. Ribeiro; R. Kaztman (orgs.), A Cidade Contra a Escola? Segregação Urbana e Desigualdades Educacionais em Grandes Cidades da América Latina. Rio de Janeiro, Letra Capital, pp. 33-58.

THUROW, Lester C. (1972), "Education and Economic Equality". The Public Interest, no 28, pp. 66-81.

VALLADARES, Licia. (2000), “A Gênese da Favela Carioca. A Produção Anterior às Ciências Sociais". Revista Brasileira de Ciências Sociais, vol. 15, no 44, pp. 5-34.

WACQUANT, Loïc. (2001), Os Condenados da Cidade: Estudo sobre Marginalidade Avançada. Rio de Janeiro, Revan.

WILSON, William Julius. (1987), The Truly Disadvantaged: The Inner City, the Underclass, and Public Policy. Chicago/London, The University of Chicago Press. 


\section{RESUMO}

\section{Território e Desigualdades de Renda em Regiões Metropolitanas do Brasil}

O objetivo deste artigo é contribuir com o debate acerca das desigualdades de renda do trabalho nas regiões metropolitanas brasileiras, incorporando nos seus determinantes explicativos a localização residencial dos indivíduos na metrópole. As desigualdades de renda são analisadas a partir do contraste de três modelos de regressão linear múltipla - Mincer, Credencialismo e sobre-educação -, segundo os dados da Pesquisa Nacional por Amostra de Domicílios (PNAD) do Instituto Brasileiro de Geografia e Estatística (IBGE), de 1998, 2003 e 2009. Constatamos que a localização residencial dos indivíduos na metrópole tem efeito na explicação das desigualdades de renda e pode ser avaliada pela dupla escala da divisão social do território, segundo os modelos núcleo-periferia e favela-não favela. A análise dessa dupla escala demonstrou-se importante para gerar elementos empíricos que nos permitissem construir hipóteses sobre os mecanismos que explicam as diferenças entre os indivíduos na obtenção de renda do trabalho, a partir das contribuições analíticas do campo disciplinar da sociologia urbana, em especial, referente às contribuições dos estudos sobre efeitos de vizinhança.

Palavras-chave: desigualdades de renda; efeitos de vizinhança; modelo núcleo-periferia; modelo favela-não favela; metrópole

\section{ABSTRACT \\ Territory and Income Inequality in Metropolitan Regions in Brazil}

The aim of this article is to contribute to the debate concerning inequalities in income earned from labor in Brazilian metropolitan regions, incorporating among its determinants the residential location of individuals. Income inequalities are analyzed based on the contrast between three models of multiple linear regression - Mincer, Credencialismo and over-education according to the data from the Pesquisa Nacional por Amostra de Domicílios (PNAD), conducted by the Instituto Brasileiro de Geografia e Estatística (IBGE) in 1998, 2003 and 2009. We observed that residential location in the metropolis has an effect in the explanation of income inequalities and can be assessed by means of a two-fold scale of the social division of territory, according to the nucleus-periphery model and the favela-not favela model. The analysis of this double scale proved important in generating empirical tools that made it possible to construct hypotheses concerning the mechanisms that explain the differences between individuals in terms of income based on analytical contributions from the field of urban sociology, particularly studies on the effects of neighborhood.

Keywords: income inequality; effects of neighborhood; periphery-nucleus model; favela-not favela model; metropolis 


\section{RÉSUMÉ}

\section{Territoire et Inégalités de Revenu dans les Métropoles Brésiliennes}

L'objectif de cet article est de contribuer au débat sur les inégalités de revenu du travail dans les métropoles brésiliennes en incorporant à leur explication le lieu de résidence des habitants du tissu urbain. Les inégalités de revenu seront ici analysées à partir du contraste de trois modèles de régression linéaire multiple - Mincer, crédentialisme et sur-éducation -, en se basant sur les données de Pesquisa Nacional por Amostra de Domicílios (PNAD) de Instituto Brasileiro de Geografia e Estatística (IBGE) de 1998, 2003 et 2009. Nous avons constaté que l'adresse des individus au sein des zones urbaines a une incidence sur les inégalités de revenu et peut être analysée à partir du double niveau de la division sociale du territoire, à savoir les modèles centre-périphérie et favela-non favela. L'analyse de ce double niveau de distinction s'est révélée indispensable pour générer des éléments empiriques nous permettant de construire des hypothèses sur les mécanismes qui peuvent expliquer les différences entre les individus en matière de revenus du travail. Nous ferons appel aux contributions analytiques du domaine de la sociologie urbaine, et en particulier à celles des études sur les effets de voisinage.

Mots-clés: inégalités; effets de voisinage; modèle centre-périphérie; modèle favela-non favela; métropoles

\section{RESUMEN}

\section{Territorio y Desigualdades de Renta en Regiones Metropolitanas de Brasil}

El objetivo de este artículo es contribuir con el debate sobre las desigualdades de renta del trabajo en las regiones metropolitanas, incorporando en sus determinantes explicativos la localización residencial de los individuos en la metrópoli. Las desigualdades de renta son analizadas a partir del contraste de tres modelos de regresión linear múltiple - Mincer, Credencialismo y sobre-educación, según los datos de la Pesquisa Nacional por Amostra de Domicílios (PNAD) del Instituto Brasileiro de Geografia e Estatística (IBGE), de 1998, 2003 y 2009. Constatamos que la localización residencial de los individuos en la metrópoli tiene efecto en la explicación de las desigualdades de renta y puede ser evaluada por la doble escala de la división social del territorio, según los modelos núcleo/periferia y favela/no favela. El análisis de esta doble escala es importante para generar elementos empíricos que permitan construir hipótesis sobre los mecanismos que expliquen las diferencias entre los individuos en la obtención de renta del trabajo, a partir de las contribuciones analíticas del campo disciplinar de la sociología urbana referente a las contribuciones de los estudios sobre efecto vecindario.

Palabras clave: desigualdades de renta; efecto vecindario; modelo núcleo-periferia; modelo favela-no favela; metrópoli 


\section{$B R E S I L(S)$}

ISSN 2257-0543

REVISTA SEMESTRAL

$n^{\circ} 8$ - Classes sociales et rapports de classes

Novembro de 2015

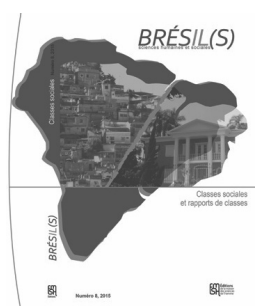

\section{Dossier « Classes sociales et rapports de classes »}

Christophe Brochier et Carolina Pulici

L'étude des classes sociales et des rapports de classe au Brésil

Nicolas Fayette

Les rapports de classe dans les approches ethnographiques de la sociologie brésilienne

Frédéric Lebaron et Lucas Page Pereira

Outils statistiques, outils d'analyse : les nomenclatures socioprofessionnelles et les classes sociales en Europe et au Brésil

Camila Giorgetti

Comment les catégories supérieures de São Paulo parlent-elles de leurs employées domestiques ? Analyse d'un rapport de classe

Graziela Serroni Perosa, Adriana Santiago Rosa Dantas, Helena de Souza Marcon et Isamara Lopes Rocha Cruz

Transformations des classes populaires et de l'offre scolaire à São Paulo

Luciano Rodrigues Costa

Les relations de classes sur les chantiers brésiliens : exploitation, contr le et con ance

Maureen O'Dougherty

Ostentations vestimentaires af rmées et refusées : l'habillement à Recife comme marque de distinction sociale

\section{Varia}

\section{Cynthia Sarti}

La victime et le témoin durant la dictature militaire au Brésil : une anthropologie de la mémoire

\section{Rodrigo Patto Sá Motta}

Les images de la police politique (DOPS) : utilisations, appropriations et controverses

Diogo Arruda Carneiro da Cunha

De la « Semaine révolutionnaire » à la « Révolution » de 1964 : itinéraires, réseaux et lieux de sociabilité de la " génération de 1922 »

\section{Brésil(s) existe em versão electrônica : bresils.revues.org}

\section{Números avulsos : $16 €$}

\section{Condições de compra}

Particulares: pela internet no "Comptoir des presses" - www.Icdpu.fr ou no site da editora - www.editions-msh.fr Institucionais: + cid@msh-paris.fr ou 2 + 33 (1) 53482095

Assinatura

CRBC - EHESS - 190-198 avenue de France - 75244 Paris cedex 13 - bur. 420 Responsável pelas assinaturas: Dominique Duchanel ( + 33 (1) 49542219 - + bresils-revue@ehess.fr Preço (2 números por ano) França: individual $29 €$ - institucional $35 €$ Exterior: individual $36 €$ - institucional $40 €$ 